\title{
MODERNIDAD Y VANGUARDIA EN LA LITERATURA MEXICANA:
} ESTRIDENTISTAS Y CONTEMPORANEOS

\author{
POR \\ SAMUEL GORDON \\ U.N.A.M.
}

Al igual que en otras literaturas, también la historiografía literaria mexicana deja entrever desacuerdos evidentes al pasar revista a muchos de los acontecimicntos y grupos que coincidicron en el panorama litcrario durante la treintena de años que generalmente se asignan a la proliferación de las vanguardias y la llamada nueva litcratura.

Determinar y circunscribir las corrientes vanguardistas que Hispanoamérica en gencral -y México en particular- adaptó y reprodujo o adoptó y produjo, presenta la inmediata incomodidad de intentar homologar la disparidad de ritmos históricos nacionales y, al ticmpo, la imposibilidad de soslayar que, también a nivel nacional - y cs cste cl caso mexicano- cocxisticron tendencias hetcrogéneas, cntre las cuales las vanguardias tuvicron manifestaciones aisladas o menores. Así, mientras la vanguardia irrumpia en Argentina, Chile, México y Pcrú; Paraguay vivía plácidamente su modernismo, que también profesaban no pocos autores de csos países.

Para nuestra postcrior cvaluación de los alcances y logros de la vanguardia, conviene rememorar aquí que la hoy ya imprecisa y excesivamente gencralizadora metáfora de primigenio contenido militar, sugeria cicrta marcha de aproximación y reconocimiento, o exploración de un terreno difícil y desconocido. La mayoría de los artistas de vanguardia buscaron dilatar los umbrales estéticos mediante el cjercicio de una actividad experimental, rotulada con fórmulas y expresiones provenientes de la tecnología científica $\mathrm{e}$ industrial de entonces. En términos puramente literarios, buena parte del hermetismo lingüístico, formal y estilístico que conllevaban los experimentalismos y tecnicismos, devinieron en una de las caractcrísticas más notorias de la vanguardia. Un amplio espectro crítico internacional, desde cl inglés William Empson al ruso Víctor Schklovski, consideraba que la pocsía - género que aqui privilegiamos - tendía a desarrollar un lenguaje cquívoco, en su búsqueda de efectos de "ambigüedad". Ello contribuyó a marcar al arte y la literatura de vanguardia con un dejo de impopularidad. Ya veremos 
cómo, en cl caso mexicano, dio pie a los enconados y frecuentes reproches que una vanguardia de corte político endilgó a la vanguardia litcraria.

Recordemos tambićn que, en México, csic fenómeno coincidió con cl periodo i mmediato de la posrevolución y conjuntó, abruptamente, a epigonos del modernismo con nucvos ismos diversos, incluyendo a los dos grupos mediante los cuales cxaminaremos algunos aspectos de la vanguardia que siguió al modernismo. De aquella extraña - y las más de las veces forzada-convivencia entre modernistas, atencístas, colonialistas, nativistas, agoristas o simples individualistas, surgicron todo tịno de pugnas, disensiones y polémicas de las cuales subsisten algunos ecos que permean hasta hoy muchos enfoques críticos.

Las discrepancias primordiales abarcan desde los integrantes hasta las filiaciones estéticas de diferentes grupos que, aunque generalmente reunidos en tomo a revistas litcrarias o csferas de influencias y mecenazgos, así como lambién mesas de cafés ${ }^{1}$, parecen haber dado pic a variadas acepciones - amplias o estrechas-

1 Precisamente por no ocuparnos en el presente trabajo de la destacada importancia que tuvicron para los grupos que aquí estudiamos las tertulias de café, cabe al menos, anotar lo siguiente; Los cafés La Flor de México, Los Monotes, Europa, Lady Baltimore, Sanborn's y Café París resultaron fundamentales en la gestación y marcha de muchos proyectos literarios y editoriales. Así desde abril de 1923, el grupo Estridentista comenzó a reunirse en el café Europa de la colonia Roma. Este establecimiento pasaría a la historia literaria de México con el nombre de "El Café de Nadie" bautizado así por Ortega y sobre cl cual Arqueles Vela escribiría luego una novela con el mismo título. Entre los clientes más asiduos se contaban Maples Arce, Arqueles Vela, Salvador Gallardo, Germán List Arzubide cuando venía de Puebla, Luis Marín Loya, Febronio Ortega, Miguel Aguillón Guzmán, Gastón Dinner, Francisco Orozco Muñoz, los músicos Manuel M. Ponce y Silvestre Revucltas, y del grupo de pintores allegados, Diego Rivera, Leopoldo Méndez, Germán Cueto, Ramón Alva de la Canal, Jean Charlot y Fermín Revueltas. Para ayudar a conseguir clientela a su hermano Luis, José Clemente Orozco decoró el café que éste abrió en la calle República de Cuba, en las proximidades de República de Chile, con dibujos de brillante colorido y gran tamaño - y de ahí su nombre Los Monotes - pintando las figuras más refinadamente populares. Se decía en la época que ni los muros de la Secretaría de Educación Pública tenían el interés pictórico de aquel café bohemio. Durante buena parte de la década de los Veinte mađuraron en sus mesas muchas inquictudes pictóricas, musicales y literarias, tanto de mexicanos como de extranjeros según recuerda Salvador Novo. Similar papel de cuasi oficina cumplieron el Lady Baltimore y el Sanborn's. Como recuerda Ermilo Abreu Gómez se reunían todos los sábados - hasta abril de 1929- la plana mayor de Contemporáneos para hacer allí su revista. Durante más de quince años, de 1930 a 1945 , el Café París fue otro de los centros importantes de la vida literaria y artística de la $\mathrm{Cd}$. de México. La revista Letras de México se hacía prácticamente allí. Asistían con regularidad Octavio Barreda, Javier Villaurrutia, Celestino Gorostiza, Samuel Ramos, Antonio Magaña 
de los grupos en cuestión. Hay que agregar aqu, lo ya dicho respecto a la frecuente confusión que propició cl México posrevolucionario, cntre vanguardismo cstético y vanguardismo político, cuyas exigencias fucron más acentuadas y urgentes que en otras partes. Frecuente tributaria de los vaivenes políticos, la historia de la cultura de este período, no pudo sustracrse de esta sujeción. Añadamos que también ha sido asiduo privilegiar a los poctas, en detrimento o franca exclusión de quienes practicaron oưos géncros, quizá, porque como advertía Guillermo de Torre "la pocsía mexicana en cl mapa de América y a diferencia de otras expresiones artísticas, particularmente la pintura, representa la mesura, la contención. De ahí que los brotes vanguardistas [...] tuvieron un carácter de algo cxcepcional y aún contracorricnte"?

Comencemos por situar e interrelacionar a algunos cscritores, artistas $\mathrm{e}$ intelectuales que, nacidos entre 1897 y $1907 \mathrm{cn}$ diversos puntos del país, coincidieron en la Escucla Nacional Preparatoria de la capital durante los años inmediatamente posteriores a 1917 -fecha generalmente considerada como de legitimación del proceso revolucionario- iniciando una nueva ćpoca de la cultura mexicana: la posrevolucionaria. Gilberto $O w e n$ nos recuerda que en la clapa que siguió a la revolución, algunos de aquellos jóvenes eran cconomistas, otros cran campesinos, otros ingenicros o artistas, "todos ćramos original, esencialmente, revolucionarios, y sentíamos no necesitar de membrete que lo pregonara [...] Nacidos, crecidos en respirar aquel aire joven de México, nos identificaba un afán de construir cosas nuevas, de adoptar posturas nuevas ante la vida. Sentíamos esto lo único revolucionario y más sinccro que tomar simplemente lo vicjo y barnizarlo y escribir cncima: 'iViva la Revolución!' [...]"3.

Tambićn Ortiz de Montellano advertía que "El tema de la Revolución Mexicana presenta interesantes, ilimitados aspectos. [...] La juventud mexicana dedicada a la litcratura, la oratoria [...], no importa cl derrotero de sus afirmaciones, es de origen, revolucionaria, porque las normas que scñalan su desarrollo vital

Esquivel, Carlos Luquín y con menos frecuencia Jorge Cuesta, Elías Nandino, José Gorostiza, Bernardo Ortiz de Montellano y Rodolfo Usigli. Octavio Paz recuerda que el Café París tuvo dos épocas. La primera, en la calle de Gante, cuando lo frecuentaban los nombrados y la segunda, en la calle Cinco de Mayo.

${ }^{2}$ Guillermo de Torre, Mistoria de las literaturas de vanguardia. II (Madrid: Ediciones Guadarrama, 1971), p. 272.

3 Gilberto Owen, "Poesía y revolución", en Lecturas Dominicales, suplemento de El Tiempo, Bogotá, 25 de febrero de 1934. Citado por José Luis Martínez en su "Presentación" de Contemporáneos, [Edicion facsimilar], Vol. I, (1981), pp. xv-xvi. 
nacieron y se moldearon dentro del ambiente nuevo de México. Nucstros actos, ideas y sentimientos siguen, fatalmente, las nuevas corrientes de la vida nacional".

Desde que los primeros pasos del juvenil grupo "Orchabada"s cuajaron en torno a la cfímera revista Gladios [1916] ${ }^{6}$, pasando por las páginas de San-Ev-Ank [1918] y Examen [1932], revista que concitó odios y escándalos periodísticos, hasta Letras de México [1937-1947] y El Hijo Pródigo [1943-1946], últimas contribuciones de Octavio $\mathrm{G}$. Barreda al universo de las revistas litcrarias de México, la mayoría albergó en sus páginas colaboraciones de buena parte de los autores que nos ocupan?.

La revista México Moderno [1920-1923] — generalmente disociada de los grupos literarios que examinamos aquí-, constituye una interesante muestra de la compleja confluencia de corrientes y generaciones en la simultancidad de una publicación periódica abicrta y heterogénca. Dirigida por Enrique González Martínez, contó entre sus redactores y colaboradores a escritores tan distintos como Pedro Henriquez Ureña, Antonio Castro Leal, Alfonso Caso y Vicente Lombardo Toledano - del grupo de los "Sicte Sabios"-, junto a jóvenes como Salvador Novo, José Gorostiza, Jaime Torres Bodet y Samuel Ramos, que más tarde constituirían los núcleos de las revistas Ulises [1927-1928] y

4 Bernardo Ortiz de Montellano, Obras en prosa. (México: Universidad Nacional Autónoma de México, 1988), [Recopilación, edición, preliminares, notas e índices de María de Lourdes Franco Bagnouls], p. 232.

${ }^{5}$ El grupo "Orchabada" reunió a Enrique Ortega Flores, los hermanos Carlos y Eduardo Chávez, Octavio Gabino Barreda y Guillermo Dávila. Al go alejados se hallaban también Carlos Pellicer y Luis Enrique Erro. Solían reunirse en casa de los Chávez ubicada en la Plaza de Santísima, hoy calle República de Guatemala. Para información adicional al respecto véase el estudio introductorio de María de Lourdes Franco Bagnouls en: Octavio G. Barreda, Obra. Poesía. Narrativa. Ensayo. (México: Universidad Nacional Autónoma de México, 1985), [Recopilación, edición, introducción, notas e índices], en particular pp. 18 y ss.

6 En Gladios participaron activamente Luis Enrique Erro, Octavio G. Barreda, Carlos Pellicer, Carlos Chávez, Guillermo Dávila y Eduardo Chávez. El sostén financiero fue posibilitado por el gobierno mediante los oficios del entonces Ministro de Instrucción Pública, Ing. Félix F. Palavicini. La efímera vida de Gladios se redujo a dos números que totalizaron 186 páginas incluyendo las siguientes secciones: cientílica, arte, música, literatura, historia y bibliografía.

${ }^{7}$ Con excepción de La Nave [1916] y habida cuenta de la natural exclusión de las publicaciones adversas - una vez delimitados los principales grupos antagónicos-como Crisol [1929-1952], las restantes, desde Pegaso [1917] y San-Ev-Ank [1918] hasta las ya citadas, casi todas recibicron y divulgaron colaboraciones de los autores que examinamos. 
Contemporáneos [1928-1931], y escritores como Ermilo Abreu Gómcz, Carlos González Pcña, Agustin Locra y Chávez y Rafael Heliodoro Valle, quicncs, antcs y después, colaboraron en otras publicaciones, integrando los más variados grupos o distanciándose en una irreductible y aislada individualidad. Novo consideró que México Moderno fue "una publicación muy scria e importante de la época [...] [y que] fuc precisamente la extinción de México Moderno lo que hizo sentir [...] la necesidad de contar con un órgano, y la [consecuente] decisión de fundar $L a$ Falange [1922-1923] tan al mismo tiempo que la efímera Vida Mexicana [1922]."

Repasaremos suscinta y parcialmente muy contados aspectos de la vanguardia en México mediante una aproximación a dos grupos significativos: Estridentistas y Contemporáneos, que cmprendicron y desarrollaron buena parte de su trabajo literario congregados en tomo a sus respectivas revistas, y quienes se adelantaron visiblemente en su curiosidad por lo que sucedia fuera de fronteras.

En 1920, las prensas de la cditorial Cvltvra publicaron una Antología de poetas modernos de México donde se daba cabida a algunos de los jóvenes junto a poctas ya consagrados. Incluidos en una larga secuela posmodernista y bajo cl rubro específico de "Poctas del Atenco de la Juventud, 1919", aparecen reunidos por primera y premonitoria vez, conformando dos grupos claramente diferenciados, Martín Gómcz Palacio, Carlos Pellicer Cámara, Bernardo Ortiz de Montcllano, José Gorostiza Alcalá, Enrique González Rojo, Jaime Torres Bodet y, como integrantes del Atenco, pero separados de los anteriores, Luciano Joublanc Rivas, Jesús Zavala, Filiberto Burgos Jiménez, Aurcliano Velázquez, Alfonso Junco, Guillermo A. Esteva y Rafacl Lozano Jr.

Aunque innúmeras - y prolongadamente insolubles- las discusiones acerca de la identidad de los anónimos compiladores de esta Antología, lo cierto cs que resulta adjudicable a terceros esta conjunción inicial'9. A partir de la conferencia

\footnotetext{
${ }^{8}$ Interesante, revelador y ecuánime resulta el critcrio de ordenación cronológica del índice. En scis apartados se agrupa la labor poética de México desde el Modernismo y hasta la fecha de elaboración de la antología — 1920 - según la secuencia siguiente: I. Poctas de la Revista Azul, 1894. II. Poetas de la Revista Moderna, 1898-1911. III. Poetas del Ateneo de México, 1912. IV. Poctas de Nosotros, 1912-1914. V. Poetas posteriores al grupo del Atenco 1914-1918 y, finalmente, cl apartado VI de los poctas del Ateneo de la Juventud de 1919, que acabamos de enumerar con detalle en el cuerpo del trabajo.

${ }^{9} \mathrm{El}$ anonimato autoral —insoluble hasta la fecha - ha eludido las pesquisas de José Luis Martínez, Guillermo Sheridan y quien esto escribe. González Rojo se la ha adjudicado a Manuel Toussaint, y Sheridan ha sugerido a González Peña, González Martínez y López Velarde como posibles autores. Hasta la rara y reveladora edición de la propia casa editorial La historia de Cvltvra, 50 años de vida. (México: Editorial Cvlıvra, 1966), -en escasísimo tiro de 500 ejemplares-omite los datos del caso. Agradezco a José Luis Martínez su valiosa ayuda en esta infructuosa pero interesante búsqueda.
} 
de Xavier Villaurrutia en la Biblioteca Cervantes —el 29 de mayo de 1924—, correspondió a los propios protagonistas el intento de redibujar el mapa de la pocsía mexicana de principios de siglo y definir su lugar en ella ${ }^{10}$. En aquel análisis Villaurrutia recordó a su auditorio que hacia 1918 Enrique González Marlínez cra "cl dios mayor y casi único" de la poesia mexicana y que nuevos y "más amplios panoramas" les fueron señalados [a los jóvenes] por Ramón López Velarde y José Juan Tablada. Sin excesiva modestia y con cierta premeditación afirmó que "por la scriedad y conciencia artística de su labor, porque sintetizan, en su porción máxima, las realizaciones de un tiempo nuevo es preciso apartar en un grupo sin grupo a Jaime Torres Bodet, a Carlos Pellicer, a Oritz de Montellano, a Salvador Novo, a Enrique Gonzálcz Rojo, a José Gorostiza y a Ignacio Barajas Lozano"11. Comienza a autodelimitarse una de las primeras acepciones de lo que llegaría a ser, a la postre, cl grupo de Contemporáncos.

En aquella conferencia, se ocupó también del estridentismo: "Scría falta de oído y de probidad no dedicar un pequeño juicio al estridentismo que, de cualquicr modo, consiguió rizar la superficic adormecida de nuestros lentos procesos poćticos. Manucl Maples Arce supo inyectarse, no sin valor, el desequilibrado producto curopeo de los ismos; y consiguió ser, a un mismo tiempo, el jefe y el cjército de su vanguardia. Muy poco más tarde mereció los honores del prosclitismo - 'un prosélito es todo lo contrario de un discípulo'-. Sus afines, usando los repetidos trajes que él, repitiendo sus mismas frases, acabaron por parecérsele al grado de hacer imposible cualquicr distinción personal. Con esto, y sin proponćrsclo, Manucl Maples Arce ha logrado crcar una inconciencia poćtica colectiva, un verdadero unanimismo - muy semejante, si no fucra contrario, al que propuso en Francia Jules Romains-. Lástima que csta conclusión no haya sido previamente anunciada por los estridentistas en sus sonoros propósitos. Aunque,

${ }^{10}$ Invitado por el Departamento de Bibliotecas de la Secretaria de Educación Pública, Xavier Villaurrutia sustentó la conferencia sobre "La Poesía de los Jóvenes de México" en el Salón de la Biblioteca Cervantes en la fecha enunciada y su texto fue recogido en un opúsculo de 26 páginas que publicó la revista Antena a fines de ese mismo año.

${ }^{11}$ Con esta alusión a Ignacio Barajas Lozano (1898-1952), sobre cuya vida y obra indagó y aportó datos esclarecedores Guillermo Sheridan - véase Los Contemporáneos ayer. (México: Fondo de Cultura Económica, 1985), pp. 164-165- sugerimos instaurar un capítulo de rescate de "los olvidados" donde seguramente no debicran faltar Enrique Asúnsolo, Emmanuel Palacios, Alfonso Gutiérrez Hermosillo, que aunque se centraron en Bandera de Provincias [1929-1930] colaboraron asiduamente con los Contemporáneos, así como Miguel N. Lira, Gonzalo de León, Anselmo Mena, Alberto Quintero Alvarez y José Martínez Sotomayor. 
bicn mirado, no cs tarde para hacerlo"12. La querella estaba planteada. Los dos grupos que con el pasar de los años serían contemplados como representativos de la vanguardia en México, comenzaban a perfilarse y reconocerse como irreconciliablemente antagónicos pero, al tiempo, difcrentes de su entorno ${ }^{13}$.

Cronológicamente admitido como primer movimiento de vanguardia en México, cl estridentismo, iniciado y animado por Manucl Maples Arce, sc dio a conocer en diciembre de 1921, anunciando sus "sonoros propósitos" con el manifiesto Actual № 1. Iloja de Vanguardia. Comprimido Estridentista de Manuel Maples Arce, y extinguió su vida activa hacia 1927. A lo largo de dicho período los estridentistas publicaron -amén de cuatro manifiestos y su obra personal-cuatro intermitentes revistas: Ser [1922], Irradiador [1923], Semáforo [1924] y IIorizonte [1926-1927], además, un efímcro pcriódico, El Gladiador.

Maples Arce comenzó a poner en práctica en su poesia, una estética diferenie de la que practicaban hasta entonces modernistas y posmodernistas. Junto a imágenes futuristas introdujo clementos cubistas como "planos oblicuos", "tedios triangulares", "vértigos agudos", "paraguas cónicos" y "bohemias romboidalcs" aunque predominan en su obra $-y$ la de sus compañeros - las imágenes y meláforas provenientes del mundo industrial y mecanizado. A pesar del uso de las imágencs de corte cubista, parece no comulgar a cabalidad con los presupucstos de este movimicnto cuando prologa el libro Esquina de List Arzubide, adonde afirma que "catalogar las percepciones imaginables simples, a la mancra cubista, no constituye en la realidad, cl trascendentalismo estético de las nuevas dirccciones .... Mientras el ideal de todos los poctas contemporáneos tiende a identificarse en su cmocionalidad temática, no han podido ponerse de acuerdo en su organización interna y en su ensambladura arquitccural; todos están igualmente de acuerdo, cuando menos, tcóricamente, en que tanto la poesía como la pintura, etc., tengan un pleno sentido equivalente. Crear y no copiar"14.

List Arzubide por su parte pregonaba que "las arquitccturas magníficas de Nucva York con su distribución del volumen, con su geométrica distribución de las masas, arrebataba al mundo y nosotros licgamos a formar en las filas de los que entendían la canción del hierro, del radio, de la velocidad y de la multitud"15.

La mayoría de los jóvenes que se acercaron a este movimiento conocían

${ }^{12}$ En la ya citada cdición de Antena a pp. 15-16.

${ }^{13}$ Tal grado alcanzó el antagonismo entre ambos grupos que tiempo después, en Cuba, Manach todavía hablaba a favor de Maples Arce, en tanto que Lezama Lima lo hacía a favor de los Contemporáneos.

1 Esquina. Poemas de Germán List Arzubide. "Margen" de Manuel Maples Arec. (México: Librería Cicerón, 1923).

${ }^{15}$ Citado por José María Benítez, "El Estridentismo, El Agorismo, Crisol." En: Las Revistas Lilerarias de México. (México: Instituto Nacional de Bellas Artes, 1963), p. 149. 
bastante de lo que estaba sucediendo en Europa y también en otras latitudes de Amćrica. Comparticron con dadaístas, futuristas y otros "istas", la afición y cl deslumbramiento por el dinamismo mecánico, la exaltación del automóvil, del tren y del acroplano; que tan agudamente circunscribió Renato Poggioli al precisar que más que idolatría de la maquína-vehículo, iba en dirección de la modernolatría que acuñaron los futuristas italianos ${ }^{16}$.

Pucstas en marcha algunas consideraciones estéticas, se trató de imprimirle al movimiento cicrto carácter nacional, instalando una especie de sede en la ciudad de México, en Donceles 69 - Laller del pintor Huberto Ramírez- aunque en la práctica "scsionó" de mancra permanente hasta cl traslado a Xalapa, en cl cafć "Europa", rebautizado por Ortega y Arqueles Vela como cl "Café de Nadie", en el № 160 de la antigua avenida Jalisco, hoy Alvaro Obregón. Mes y medio antes de la ya citada conferencia de Xavier Villaurrutia —el 12 de abril de 1924 , los cstridentistas inauguraron una exposición en ese café, cxhibiendo cuadros de Ramón Alva de la Canal, Leopoldo Méndez, Jcan Charlot, Rafacl Sala, Emilio Amero, Fermín Revuclas, Xavicr González y Máximo Pacheco; máscaras "estridentistas" de Germán Cucto y csculturas de Guillermo Ruiz. Leycron sus poemas Maples Arce, List Arzubide, Salvador Gallardo, Humberto Rivas, Luis Ordaz Rocha, Luis Felipe Mena y Migucl Aguillón Guzmán. Arqueles Vela cerró con una lectura de su novela El Café de Nadie ${ }^{17}$.

Singular aportación a la historiografía literaria sobre cl movimiento estridentista sc halla en la autodefinición proporcionada por Arqueles Vcla, uno de sus principales protagonistas, en un texto donde omitc mencionar a los Contemporáncos con la sola excepción de Gorostiza, cuando recuerda a sus Iectores que fue en América donde "antes que muchos españoles volvieran a su tradición popular, Josć Gorostiza rctornaba en Canciones para cantar en las barcas, a una clapa olvidada en la pocsía cspañola. [Esta frase recuerda la presentación de Gorostiza en la Antología de Jorge Cuesta]. Paralela acsa corriente popular surge en América una tendencia hacia la pocsía de influencia filosófica, intelectualista. Contra esa manifestación pasiva, actitud desligada de la realidad social, irrumpió cl Movimiento iniciado por Manucl Maples Arce con su Compri-

\footnotetext{
${ }^{16}$ Renato Poggioli, Teoría del arte de vanguardia. (Madrid: Revista de Occidente, 1964), [Traducción del italiano por Rosa Chacel], p.50.

${ }^{17}$ Además de los nombrados, se suele adjudicar al grupo estridentista - bien como integrantes, bien como allegados o, simples simpatizantes - a los siguientes escritores: Luis Quintanilla, Francisco Orozco Muñoz, Gerardo García, Enrique Barreiro Tablada, Mario Ponzón Ribera y José Luis Díaz Castilla. A los artistas plásticos Javier Gucrero, Julio de la Fuente y Gabriel Fernández Ledesma.
} 
mido Estridentista y su libro de poemas Andamios interiores. El estridentismo se diferencia[ba] de otros movimicntos de vanguardia en su posición actualista. Intentaba crear un arte para el presente y no para el pasado. El ultraísmo español, cl futurismo italiano proclamaron un arte más allá de la realidad inmediata; el estridentismo, un arte circunstancial y de tendencia; un arte de lucha. Fuc un levantamiento litcrario de carácter anarquista, con visos románticos. Maples Arce cra más social; List Arzubide más popular, en su poesia de lucha; Arqueles Vela, cl más destructor; cl que mayor influencia maquinística reflejaba. Esquina, de List Arzubide encuentra la temática más allá de los cuatro muros de la existencia apasionante de la poesía joven. La inquictud estridentista se cchaba a la calle, a las plazas públicas, a la búsqueda de la nucva belleza. Maples Arce alcanzaba un cstilo de cstructura tensa de imágenes, List Arzubide es más idea que forma. Arqucles Vela contiene más valores sensuales [...] La señorita etc. cs una novela que describe la vida tumultuosa y mecanizada interior creada por cl industrialismo y la mecanización del hombre en la socicdad contemporánca"18.

Buscando aceleradamente superar la modernidad, aquellos jóvenes instauradores de la vanguardia - de ambos grupos- intentaron situarse en una perenne "contemporancidad" revelando ciertas predilecciones terminológicas, así como c1 asiduo y recurrente uso de formas y artefactos de la vida "ultramoderna". Entre otros clementos inicialmente comuncs a Estridentistas y Contemporáncos, dos de los que más destacan son -insistimos en recordarlo- el reconocimiento a los adcudos con José Juan Tablada y Ramón López Vclarde, y un empeño infatigable por integrarse a su "contemporancidad", cualesquicra fucran la filosofía y la forma en que la interpretaran separadamente. Hacia 1926, los Estridentistas publicaron en su cuartel general de Xalapa, cl primer número de la revista IIorizonte cuyo subtítulo la presentaba al lector como una Revista mensual de actividad contemporánea. En la contraportada, su dircctor, Germán List Arzubide aclaraba que todo "lo que signifique una manifestación de la actividad contemporánca, hallará en clla lugar y atención".

La obstinada búsqueda de incorporación a la contemporancidad que impregnó desde principios de siglo buena parte del quehacer intelectual de quienes ni en su país, ni en cl continente ni en Europa se conformaban con la modernidad a secas, se extendió tempranamente por la América hispana. La primera publicación mexicana que reflejó esa búsqueda desde su propio nombre fuc, hasta nueva noticia, precisamente la Revista Contemporánea que comenzó a publicarse quincenalmente en encro de 1909 en Monierrey, Nuevo León ${ }^{19}$. Con el patrocinio de

\footnotetext{
${ }^{18}$ Arqueles Vela, Evolución histórica de la literalura universal. (México: Ediciones Frente Cultural, 1941), pp. 359 y ss. Existe una segunda edición de 1951.
} 
don Virgilio Garza, dirigió la revista cl colombiano Ricardo Arenales, mejor conocido como Porfirio Barba-Jacob. Todo parece indicar que el nombre lo propuso Arcnalcs, tomándolo de otra revista homónima que publicaba Baldomcro Sanín Cano en Bogotá y que circuló en México, a juzgar por alguna reseña en la Revista Moderna ${ }^{20}$. Cicrtamente el concepto y la denominación se hallaban muy presentes y difundidos también en otras latitudes. Desde la Contemporánea que dirigió Gorki en Rusia en 1909 hasta aquella otra Revista Contemporánea que apareció en el extremo austral del continente americano, en Santiago de Chilc y que publicó - entre novicmbre de 1910 y marzo de 1911 - Pedro Prada Calvo, el nombre estuvo muy en boga mucho antes de que se fundara la revista que aquí cstudiamos. Lo que hay que recordar de la revista regiomontana, a nucstros efectos, es que cntre los cscritores y artistas que congregó se contaron dos hombres de pluma importantes por su influencia indirecta en los jóvenes que nos ocupan: Enrique Fernández Ledesma y Alfonso Reyes ${ }^{21}$.

Algunos de aquellos jóvenes atentos a la "contemporancidad" del entorno litcrario intcrnacional fundarian en 1928 la editorial y revista Contemporáneos - bajo cuyo nombre se sucle rotular, reconocer y privilegiar a un númcro - sicmpre variable y debatido- de poctas y cnsayistas connotados excluyendo, por diversas razones, a ouros que comparticron por igual páginas de publicaciones comunes, tertulias de café, antagonismos literarios y políticos, afinidades y polémicas, pero que practicaron, notoriamente, géneros literarios o arlísticos diferentes de los nombrados. Coincidicron con la aparición de la revista —de hecho la precedicron ligeramente--, el libro homónimo de Jaime Torres Bodet - donde se reafirmaba a los integrantes del grupo como un "grupo de soledades"- y la Antología de la poesía mexicana moderna de Jorge Cuesta, que a mancra de manificsto militante excluía de su selección nombres "intocables" c incluía - con exccsiva y ostensible desproporción-a las novísimas "soledades" del flamante archipićlago.

El grupo más inmediatamente asociado con los Contemporáncos sucle conformarse mediante las siguientes fusiones: la integrada por los nacidos entre $1897 \mathrm{y}$ 1902 donde sucle incluirse a Carlos Pellicer Cámara (1897-1977), a Enrique

\footnotetext{
${ }^{19}$ El primer número de la Revista Contemporánea se publicó el cinco de enero de 1909. Aparecieron en total catorce números; el último, el veinte de julio del mismo año.

${ }^{20}$ Véase la reseña publicada en la Revista Moderna, (Vol. IV, № 2) de abril de 1905, pp. 124-125.

21 Entre los jóvenes escritores y artistas de la ciudad que aglutinó en su torno la revista regiomontana, además de los nombrados, se contaron Joel Rocha, Fortunato Lozano, Héctor González, Francisco Ramírez Villareal, Federico Gómez y Juan B. Delgado.
} 
Gonzálcz Rojo (1899-1939), a Bcrnardo Ortiz de Montellano (1899-1949), José Gorostiza Alcalá (1901-1973) y Jaime Torres Bodet (1902-1974). El grupo siguiente se constituyó a partir de 1917 reuniendo a los nacidos entre 1903 y 1904. Enćl suclc incluirse a Xavicr Villaurrutia (1903-1950), Jorge Cucsta (1903-1942), Gilberto Owen (1904-1952) y Salvador Novo (1904-1974). La cronología de incorporación - y posterior fusión- de este scgundo grupo se ubica también cn 1917, fecha en que José Gorostiza llegó a la capital desde Aguascalientes, trabando amistad con los primeros y coincidiendo con la llegada de Novo desde Torreón a la ciudad de México, año en que conoció a Villaurrutia y formaron lo que Novo đenominó "la generación bicápite". También en 1917 arribó Samucl Ramos desđe su natal Michoacán para incorporarse a la Escucla Nacional Preparatoria. En 1921 se les sumó Jorge Cuesta, originario de Córdoba, Veracruz, y en 1923, cl sinalocnse Gilberto Owen, procedente de Toluca ${ }^{22}$. Entre julio y noviembre de 1924 aparecen ya rcunidos colaborando en la cfímera revista Antena que fundó y dirigió Francisco Monterde, a quicn sucle asociarse con los escritores llamados "colonialistas"23.

Como sucle suceder con la mayoría de los grupos delimitados y denominados tambićn desde "fucra" de los mismos, la vaguedad que conlleva la designación Contemporáncos despicrta controversias en numerosos aspectos. Dos de los más notorios giran en torno a quicnes realmente integraron el grupo. ¿Grupo? También capilla, cenáculo, tendencia, generación, constelación y hasta mafia se cuentan cntre los innúmeros calificativos utilizados por propios y ajenos - endógenos y exógenos-, para denominar a csta conjunción intelectual, sobre cuya importancia cn cl quehacer litcrario y la definición del perfil de México cn aquellos años y los subsecuentes, cl consenso es hoy unánime. Naturalmente, la perplejidad desconcertó también a bucna parte de los propios implicados. Así, por cjemplo, Carlos Pellicer sostuvo en 1948 que no tenía nada que ver con cl grupo: "soy anterior [...] tenía yo obra impresa cuando 'Los Contemporáneos' no se habían dado a conocer"24. En 1956 afirmó lo contrario: "por mi generación pertenezco al grupo

22 Véase Sheridan, p. 160 y César Rodríguez Chicharro, "Los Contemporáneos (19201932)", cn: Estudios de literalura mexicana. (México: Universidad Nacional Autónoma de México, 1983), particularmente, pp. 119 y ss.

${ }^{23}$ Conjuntamente con Francisco Monterde sucle incluirse en este grupo de escritores que ambientó parte de su narrativa en el período de la Colonia o Novohispano - y de ahí la denominación de "colonialistas"-_a Artemio de Valle Arizpe, Julio Jiménez Rueda, Ermilo Abreu Gómez, Mariano Silva y Áceves, Manuel Horta y Jorge Godoy. Véase al respecto la información proporcionada por el propio Monterde en Personas, revistas y diarios. (México: Universidad Autónoma Metropolitana, 1982), [Recopilación y entrevistas por José Martíncz Torres], p. 22. 
de Contemporáneos que alrededor de la revista de ese nombre piloté Xavicr Villaurrutia. Sin cmbargo, me hallaba en Roma cuando nació aquella publicación y sólo colaboré con poemas en un número de sus postrimerías. Propiamente Contemporáncos no tenía unidad de orientación. Fue como Villaurrutia la definió, un grupo sin grupo. Ahí estuvicron Novo, Torres Bodet, Jorge Cucsta -mucrto en plena juventud-, quienes fueron con Villaurrutia los mejores hombres de letras del grupo. Pero mi gencración ha sido directamente afectada por la revolución. Pocos logramos tílulos universitarios, algunos ni siquiera ilegaron a sus aulas. Otros debicron abandonar las profesiones, sin optar sus grados. Cada uno tomó $\mathrm{cl}$ rumbo que su sentimicnto de la vida y las circunstancias le señalaron"25. Elias Nandino (1900), otro "contemporánco" para la mayor parte de la crítica, fue cxtremadamente duro en alguna ocasión, al opinar sobre cl grupo: "Ios Contemporáncos [fueron] una 'mafia' inteligentemente llevada para que triunfaran sicte personas a través de los esfuerzos de quien fucra. Los Contemporáncos 'fucron' porque había mucha gente que valía que lics ayudaba: Agustín Lazo, que cra inteligentísimo [...]. Octavio Barreda, cmbajador en diferentes partes, quien les trajo traducciones de Saint-John Perse, de Santayana ... Las novedades, las daba Barreda [...]. Hubo muchas personas que seguian su curiosidad, pero los Contemporáncos las apartaban para que éstas no opacaran cl valor que ellos querían tener [...]" ${ }^{\prime 2}$.

Rubén Salazar Mallén (1905-1986), quien también acompañó a la mayor parte de los Contemporáncos durante largos años y soportó con cllos el cscándalo de la revista Examen, sostuvo que "la heterogencidad, más que la homogeneidad, fue su signo, por eso, las designaciones que quisicron fijar su realidad son tan varias"27.

Atendiendo, acaso, a la advertencia inicial de Cucsta en la "antologíamanifiesto" donde sugirió "no reducir la individualidad de cada objeto" puesto que "los grupos, las escuclas, se disuclven; sólo quedan los individuos que las han superado", González Casanova anotaba que "el grupo de los poetas jóvenes, cl de los 'Contemporáncos', [...] cllos mismos tuvieron cl cuidado de negar que fucra un

\footnotetext{
${ }^{24}$ Manuel Antonio Romero, "Carlos Pellicer huésped de la tierra" en: América, N 55 (1948), México, febrero 29, p. 63.

${ }^{25}$ Mario Puga, "El escritor y su tiempo: Carlos Pellicer" en Universidad de México [Revista de la], (Vol. X, N 6), febrero de 1956, p.19.

${ }^{26}$ S andro Cohen, "Elías Nandino: un siglo de rencores, amores y pocsía", en Pie de página, (Año 1, № 5), mayo-junio de 1983, p.5.

${ }^{27}$ Rubén Salazar Mallén, "Los prosistas de Contemporáneos", en Casa del tiempo, (Vol. IV, № 48), enero de 1985 , p.25.
} 
grupo cl suyo, pretendían hacer notar la destacada individualidad de cada uno en lo personal"28.

Más allá de las reincidentes y archicitadas definiciones sobre el grupo sin grupo, archipiélago de soledades y grupo de soledades, resulta oportuno y pertinente recontextualizar algunos conceptos adicionales que mercció cl grupo para la mayoría de sus propios integrantes, quienes negaron reitcradamente su existencia formal.

Reafirmando lo anticipado por su reflexión de la Antología, Cuesta escribió a Ortiz de Montellano el 12 de diciembre de 1933: "La gente acostumbra a incluirnos [...] en un grupo litcrario al que llaman 'la vanguardia', de Ulises, de Contemporáneos, por la misma razón que acaso lo llamen también de Examen. Es que no se piensa que formamos tal grupo por habernos reunido deliberadamente en torno de una doctrina artística o de un propósito definido [...] se nos reúne, se nos hace caber en un grupo sencillamente porque se evita o porque no se desca nucstra compañía litcraria. Reunimos nuestras soledades, nuestros exilios; nuestra agrupación es como la de forajidos, y no sólo en sentido figurado podemos decir que somos 'perseguidos por la justicia'29. Vea usted con que facilidad se nos siente extraños, se nos desticrra, se nos 'desarraiga', para usar la palabra con que quicre expresarse lo poco hospitalario que es para nuestra aventura literaria cl país donde ocurre. Esta condición quicre que sean nuestros personales aislamientos los que sc acompañen, los que constituyan un grupo. Nucstra proximidad es así cl resultado de nuestros individuales distanciamientos, de nuestros individuales destinos, más que de una deliberada colectividad. La aproximación que se verifica

${ }^{28}$ Henrique González Casanova, "Reseña de la poesía mexicana del siglo XX", en México en el arte, (№ 10-11), 1951, p. 17.

29 Cuesta alude al proceso judicial a que fue sometida la revista Examen que publicó capítulos de la novela Cariátide de Rubén Salazar Mallén, luego de los ataques de que fue objeto en la prensa -fundamentalmente por Excélsior y El Nacional- desde el 17 de octubre de 1932. El proceso finalizó el 20 de noviembre de ese año con la consignación de los "implicados" a un juez de lo penal "por ultraje a la moral", según instrucciones giradas por la Procuraduría General de la República. Como resultado, el Lic. Luis G. Corona cmitió una orden de aprehensión contra Jorge Cuesta — director de la revista- y Rubén Salazar Mallén —autor de la novela - el 10 de diciembre. Finalmente, el Lic. Jesús Zavala dictó una sentencia absolutoria en favor de Cuesta y de Salazar Mallén. Juzgue entonces el lector si no procede el comentario acerca de que "no sólo en sentido figurado podemos decir que somos "perseguidos por la justicia"". 
entre nosotros es como las paralelas; nos juntamos en el infinito o sea vir\{ualmente" ${ }^{330}$.

Siguicndo estas reflexiones, José Gorostiza rcafirmó que cl grupo "- ese que a falta de un nombre que lo defina, ha sido designado con una ceriera inexactitud como 'grupo sin grupo', 'de vanguardia' y 'de Contemporåncos'-, [...]. El grupo no tiene ni ha tenido nunca una cxistencia 'real' [...] ha tenido solamente insisto- una cxistencia 'virtual', no exenta, sin embargo, como toda creación mítica, de producir efectos importantes en el mundo de los hechos"’1.

Algo más condescendiente, Torres Bodet recuerda en sus memorias que "El nombre que clegimos - Contemporáneos - no tenía nada de doctrinario. En cfecto, la unidad de nuestro pequeño grupo no obedecia tanto a la disciplina de una capilla cuanto a una simple coincidencia en cl tiempo: a eso que algunos llaman la complicidad de una gencración. Nos sabíamos diferentes; nos sentíamos desigualcs. Leíamos los mismos libros; pero las notas que inscribiamos en sus márgenes rara vez señalaban los mismos párrafos. Eramos, como Villaurrutia lo declaró, un grupo sin grupo. $\mathrm{O}$, según dije, no sé ya dónde, un grupo de soledades ${ }^{32}$. No obstante, por el rigor con que descchábamos cicrtos originalcs $\longrightarrow$ defendíamos cicrtos manuscritos-, hubimos de dar, sin quererlo, la impresión de una dura homogeneidad. Se nos acusó de constituir una academia de clogios mutuos ... Bastaría recorrer la sccción crítica de Contemporáneos para percibir al contrario, la relativa y reciproca frialdad con que comentábamos nuestras produccioncs. En cuanto al exclusivismo que muchos nos reprochaban, no todo era falso $\rightarrow$ deliberadamente peyorativo - en quienes nos dirigían esa censura [...]. ¿No debicron a Contemporáneos algunos jóvenes el descubrimiento de Proust, de Joyce y de Apollinaire, la confrontación con el superrealismo, el examen de Pirandello -y sobre todo-, una actitud de consciente alerta y de vigilancia frente a sí mismos?" 33

\footnotetext{
${ }^{30}$ Jorge Cuesta, "Carta a Bernardo Ortiz de Montellano", en: Bernardo Ortiz de Montellano, Sueños. Una botella al mar. (México: Universidad Nacional Autónoma de México, 1983), [Edición y prólogo de María de Lourdes Franco Bagnouls], p. 107.

${ }^{31}$ José Gorostiza, Prosa (Guanajuato: Universidad de Guanajuato, 1969), [Recopilación, introducción, bibliografía y notas por Miguel Capistrán. Epílogo de Alfonso Reyes], pp. 182-183.

${ }^{32}$ Torres Bodet definió así al grupo en su texto "Cuadro de la poesía mexicana", incluido a páginas 33-45 de su libro Contemporáneos. Notas de crílica. (México: Herrero, 1928). La alusión específica se halla en la página 41.

${ }^{33}$ Jaime Torres Bodet, Tiempo de arena. (México: Fondo de Cultura Económica, 1955). Cito por Obras de la misma editorial p. 332.
} 
Torres Bodet se refiere primero al grupo y sintetiza luego, en breves frases, algunos alcances $\mathrm{e}$ influencias de la revista, - de la que muy poco hemos dicho y a la que bien vale asomarnos para aquilatar lo que significaron aquellos 43 números que Contemporáneos entregó puntualmente el día 15 de cada mes, durante casi cuatro años. Con un tiraje máximo $-\mathrm{c}$ infrecuente — de hasta mil quinientos cjemplares, cađa entrega osciló entre las 68 y las 123 páginas. Las cifras escuetas quedan, sin embargo, muy por debajo de la influencia que cjerció la revista en México y más allá de sus frontcras.

Junto con cl ocaso de Letras de México y El Ilijo Pródigo, y poco después del estreno en Bellas Artes el 17 de mayo de 1947 de El Gesticulador [1937], de Rodolfo Usigli (1905-1979), cste fue agredido - acaso por divergencias políticas, acaso debido a rumores insidiosos - por Salvador Novo en las escalinatas del Palacio de Bellas Artes. Para muchos, este incidente señala el hito definitivo de la disolución total del grupo de Contemporáncos. Se cerraba así cl rico y controvertido capítulo de las letras mexicanas que las condujo por la escena literaria de la modernidad y las vanguardias, hasta encaminarlas a la posmodernidad; dejando para lectores y críticos cl examen y la cvaluación del corpus litcrario acumulado durante esta treintena de años, y que aún dará mucho que hacer y no poco que discutir.

Tras la ya voluminosa acumulación de estudios, csla breve noticia historiográlica, antes que a la interpretación o valoración - tarca para la que nunca habrán de faltar panegiristas o detractores - ha tendido a rescatar voces protagónicas primordiales entretejiéndolas con coincidencias cronológicas, buscando iluminar algunos ángulos frecuentemente soslayados.

Recontextualizar ciertos aspectos estéticos de conjunto, así como recordar la labor innovadora que ambos grupos propiciaron mediante la actividad teatral experimental -a través de El Teatro Mexicano del Murciélago, cl Teatro de Ulises, cl Teatro de ahora, Escolares del Teatro y Teatro de Orientación-y cn otras tarcas más allá de lo estrictamente literario o paraliterario, ha guiado nucstro objctivo.

Recordar la dramaturgia de Usigli o las traducciones de Barreda, de Celestino Gorostiza, de Villaurrutia, de Owen, de José Gorostiza, de Jiménez Rueda, de Antonicta Rivas Mercado, de Ortiz de Montcllano, de Lcón Felipe, entre otros, cs comprender cómo un grupo ayuda a trasvasar lenguas y culturas a nucvos continentes - en ambos sentidos de la palabra - dando a conocer así, en nuestro caso a T. S. Eliot, D. H. Lawrence, Saint-John Perse, Paul Valery, Thornton Wilder, William Blakc, Nathan Asch, André Gide, Julcs Romains y Andrć Maurois entrc tantos otros, c introducir el panorama norteamericano - no sólo en sentido literario como ya lo asentaban List y Maples entre los Estridentistas y, fundamentalmente, 
Novo entre los Contemporåncos--, en un paisaje lingüístico y litcrario donde privaban lo hispano-peninsular y lo porfirianamente afrancesado de entonces.

Qucdan pucs, entre otras tareas, la de revalorar el peso que ambos grupos tienen en el panorama mexicano y su quehacer literario desde los cincuenta hasta el presente. 